\title{
Cerebrospinal fluid lactate in patients with diabetes mellitus and hypoglycaemic coma
}

\author{
HIROSHI YAO, SEIZO SADOSHIMA, YUJI NISHIMURA, KENICHIRO FUJII, \\ MITSUKO OSHIMA, TAKAO ISHITSUKA, MASATOSHI FUJISHIMA
}

From the Second Department of Internal Medicine, Faculty of Medicine, Kyushu University, Fukuoka, Japan

SUMMARY Cerebrospinal fluid (CSF) lactate and pyruvate concentrations were determined in 20 patients with diabetes mellitus but without disturbance of consciousness and five who recovered from hypoglycaemic coma. CSF lactate was slightly but significantly higher in diabetes mellitus $(1 \cdot 78, \mathrm{SEM}$ $0.04 \mathrm{~m} \mathrm{~mol} / \mathrm{l})$ than that in 15 control subjects $(1.40$, SEM $0.05 \mathrm{~m} \mathrm{~mol} / 1)$. In those who recovered from hypoglycaemic coma, CSF lactate was markedly elevated to $2.45-4.43 \mathrm{~m} \mathrm{~mol} / \mathrm{l}$. CSF glucose concentrations, however, were substantially the same between treated hypoglycaemic and diabetes mellitus groups. These findings indicate that CSF lactate levels increase with glycaemic levels in diabetes mellitus owing to enhanced glucose influx into glycolytic pathway of the brain, and also increases in treated hypoglycaemic coma probably due to mitochondrial dysfunction or damage.

It has been reported that lactate levels in CSF increase and reflect well the severity of brain dysfunction in patients with haemorrhagic or ischaemic cerebrovascular disease, ${ }^{1-5}$ malignant hypertension ${ }^{6}$ and hepatic encephalopathy. ${ }^{7}$ CSF lactate also increases in diabetic ketoacidosis with obtundation or coma. ${ }^{8}$ However, the levels of CSF lactate have not been fully investigated in relation to the severity of hyperglycaemia or diabetes mellitus, without disturbance of consciousness. Hypoglycaemia is not uncommon in diabetic patients treated with insulin or oral hypoglycaemic agents, and may cause, though rarely, serious brain damage and death. ${ }^{9}$ To examine whether glycolytic metabolism of the brain is impaired or not in diabetes mellitus, we determined CSF lactate in patients with diabetes mellitus or hypoglycaemic coma.

\section{Patients and methods}

Twenty-five patients, 20 with diabetes mellitus and five with hypoglycaemia, 16 males and 9 females, aged 52 (SEM 3) years, were studied. Of the 20 patients with diabetes mellitus, eight were well controlled (fasting plasma glucose levels

Address for reprint requests: Hiroshi Yao, Second Department of Internal Medicine, Faculty of Medicine, Kyushu University, Maidashi 3-1-1, Higashi-ku, Fukuoka, Japan 812.

Received 27 September 1988. Accepted 28 October 1988.
$<125 \mathrm{mg} / \mathrm{dl}, 87$ (SEM 6) mg/dl and were treated with diet alone except for one who was treated with 20 units of insulin daily) and the remaining 12 were fairly or poorly controlled (fasting plasma glucose $=193$, (SEM 33) $\mathrm{mg} / \mathrm{dl}$ ). The known duration of the diabetes ranged from having been discovered at the present hospital admission by an oral glucose tolerance test (five patients) to 19 years. Twelve patients demonstrated diabetic polyneuropathy with preferentially depressed vibration sense. Seven patients had a history of minor stroke including transient ischaemic attack. Lumbar puncture was performed after obtaining informed consent from each patient. In five hypoglycaemic cases who had experienced hypoglycaemic coma, CSF studies were performed 24-30 hours after immediate treatment for life threatening hypoglycaemia. The causes of hypoglycaemia were insulininduced (three patients), oral hypoglycaemic agents (one) and alcohol-induced (one). Their plasma glucose levels on admission were $22-32 \mathrm{mg} / \mathrm{dl}$ in three untreated cases, and 50$72 \mathrm{mg} / \mathrm{dl}$ in two who had been treated with glucose injection just before admission. Fifteen non-diabetic patients who had headache, dizziness or miscellaneous neurological disorders underwent lumbar puncture as a part of routine care. Since extensive examinations revealed no central nervous system disorders in these patients, the chemical indices in CSF were used as controls.

Immediately after sampling, $1.5 \mathrm{ml}$ CSF was added to the same amount of $10 \%$ perchloric acid to remove protein, and the supernatant was stored in deep freezer until estimation. After neutralisation with $3 \mathrm{~N}$ potassium hydroxide ( $\mathrm{pH} \mathrm{5.6),}$ lactate and pyruvate in CSF were analysed by the standard enzymatic methods (Boehringer, Mannheim) as previously described. $^{2467}$ All CSF samples were clear and had normal cell counts $\left(<5 / \mathrm{mm}^{3}\right)$. CSF protein and glucose concentrations were also determined. 
Table 1 Cerebrospinal fluid lactate, lactate/pyruvate ratio, in patients after recovery from hypoglycaemic coma, diabetes mellitus and control subjects

\begin{tabular}{llllll}
\hline & $\begin{array}{l}\text { Lactate } \\
(\mathrm{m} \mathrm{mol} / \mathrm{l})\end{array}$ & $\begin{array}{l}L / P \\
\text { ratio }\end{array}$ & $\begin{array}{l}\text { Glucose } \\
(\mathrm{mg} / \mathrm{dl})\end{array}$ & $\begin{array}{l}\text { Total } \\
\text { protein } \\
(\mathrm{mg} / \mathrm{dl})\end{array}$ & $n$ \\
\hline $\begin{array}{l}\text { Hypoglycaemia } \\
\text { Diabetes } \\
\text { mellitus }\end{array}$ & $\mathbf{3} \cdot 17,0.34^{*}$ & $17 \cdot 2,1 \cdot 7$ & $145,23 \dagger$ & 56,17 & 5 \\
$\begin{array}{l}\text { Controls } \\
1 \cdot 40,0.04 \dagger\end{array}$ & $15 \cdot 8,0.7$ & $96,9 *$ & $66,10 \ddagger$ & 20 \\
\hline
\end{tabular}

Values are mean, SEM. $\mathrm{n}$ : number of patients.

${ }^{*} \mathrm{p}<0.01,+\mathrm{p}<0.001$ vs. control, unpaired $t$ test.

$L / P$ ratio: lactate/pyruvate ratio.

† wo patients with diabetic neuropathy showed extremely high CSF total protein $(230$ and $131 \mathrm{mg} / \mathrm{dl})$.

\section{Results}

Table 1 summarises the average values for CSF lactate, lactate/pyruvate ratio, glucose and total protein in hypoglycaemic coma, diabetes mellitus and controls. CSF lactate was 3.17, (SEM 0.34) $\mathrm{m} \mathrm{mol} / 1$ in hypoglycaemic coma and 1.78, (SEM 0.04) for diabetes mellitus, both of which were significantly higher than 1.40, (SEM 0.05) in control subjects ( $p<0.01$ and $p<0.001$, respectively). Although slightly elevated in patients with treated hypoglycaemia, the CSF lactate/pyruvate ratio was not statistically different among the three groups. CSF glucose levels were also higher in treated hypoglycaemia and diabetes mellitus than in controls. Among diabetes mellitus patients (table 2), CSF lactate levels differed depending on the treatment, namely fairly or poorly controlled diabetes mellitus showing a higher CSF lactate (1.84, (SEM 0.04) $\mathrm{m}$ $\mathrm{mol} / \mathrm{l})$ than well controlled diabetes mellitus (1.68, (SEM 0.06), $p<0.05$ ). The history of minor stroke did not contribute to CSF lactate elevation.

In fig 1, CSF lactate and CSF glucose levels in each patient are illustrated. CSF lactate increased slightly in diabetes mellitus and more markedly in all hypoglycaemic cases recovered from coma, while CSF glucose level was substantially the same between the hypoglycaemic and the fairly to poorly controlled diabetic groups.

Table 2 Cerebrospinal fuid lactate in diabetic patients according to clinical features

\begin{tabular}{|c|c|c|c|c|}
\hline \multirow[b]{2}{*}{$n$} & \multicolumn{2}{|c|}{ Diabetes mellitus control } & \multicolumn{2}{|c|}{ History of minor stroke } \\
\hline & $\begin{array}{l}\text { good } \\
8\end{array}$ & $\begin{array}{l}\text { fair-poor } \\
12\end{array}$ & $(-)$ & $\left.7^{+}\right)$ \\
\hline $\begin{array}{r}\text { CSF lactate } \\
(\mathrm{m} \mathrm{mol} / \mathrm{l})\end{array}$ & $1.68,0.06$ & $1 \cdot 84,0.04^{*}$ & $1 \cdot 76,0.05$ & $1.82,0.04$ \\
\hline
\end{tabular}

Values are mean, SEM. $n$ : number of patients.

$*$ p $<0.05$ vs. good-controlled, unpaired $t$ test.
Illustrative case

A 47 year old Japanese man with diabetes mellitus who had been treated with $28 \mathrm{u}$ insulin daily was admitted to our clinic because of hypoglycaemic coma and transient convulsion. Although $20 \mathrm{ml}$ of $40 \%$ glucose had been administered (plasma glucose level on admission $=72 \mathrm{mg} / \mathrm{dl}$ ), he was still in deep coma. The blood pressure was $140 / 96 \mathrm{~mm} \mathrm{Hg}$ and the pulse $126 / \mathrm{min}$. After treatment with further glucose injection, he regained consciousness by the third hospital day. However, he developed psychic symptoms thereafter and died 3 months later. CSF lactate concentration estimated at 27 hours after admission was $4.43 \mathrm{~m} \mathrm{~mol} /$ 1. Postmortem examination revealed histological changes compatible with hypoglycaemic brain damage (fig 2). ${ }^{10}$

\section{Discussion}

Normal mean values of CSF lactate, reviewed by Berger and Fawer,' range from 1.58 to $2.03 \mathrm{~m} \mathrm{~mol} / 1$, which are somewhat higher than $1.40 \mathrm{~m} \mathrm{~mol} / 1$ of our control patients. Careful exclusion of diabetes mellitus might, in part, contribute to relatively low CSF lactate value in controls. An increase in CSF lactate in diabetes mellitus seems to relate with glycaemic levels. Inflow of glucose into the glycolytic pathway of the nerve cells is enhanced by elevated blood glucose, resulting in the increased intracellular and CSF lactate concentrations. " According to our previous studies, the CSF lactate concentration of $2 \mathrm{~m} \mathrm{~mol} / \mathrm{l}$ is a critical level to manifest remarkable neurological or psychic symptoms in cerebral infarction ${ }^{3}$ or hepatic encepha-

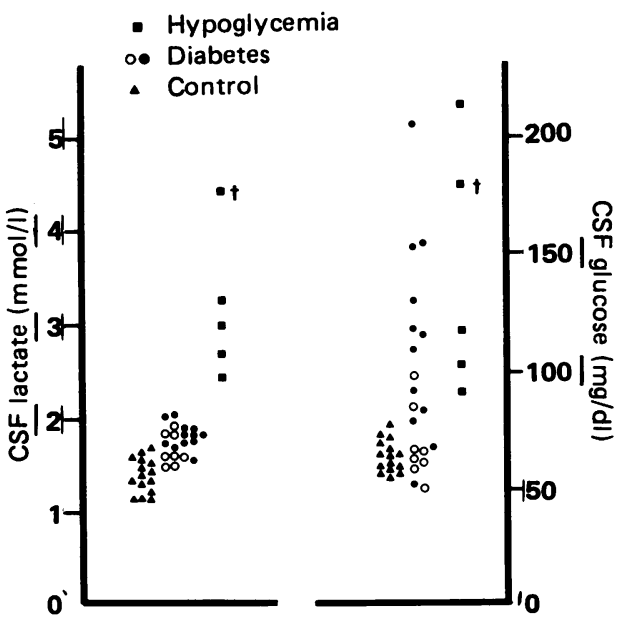

Fig 1 CSF lactate level and CSF glucose level in patients with hypoglycaemic coma ( $\square$ ), diabetes mellitus ( $\left.O{ }^{\circ}\right)$ and control subjects ( $\mathbf{\Delta})$. $\bigcirc$ : well-controlled diabetic patient, $\bigcirc$ : fairly or poorly controlled, $\uparrow:$ presented case. 


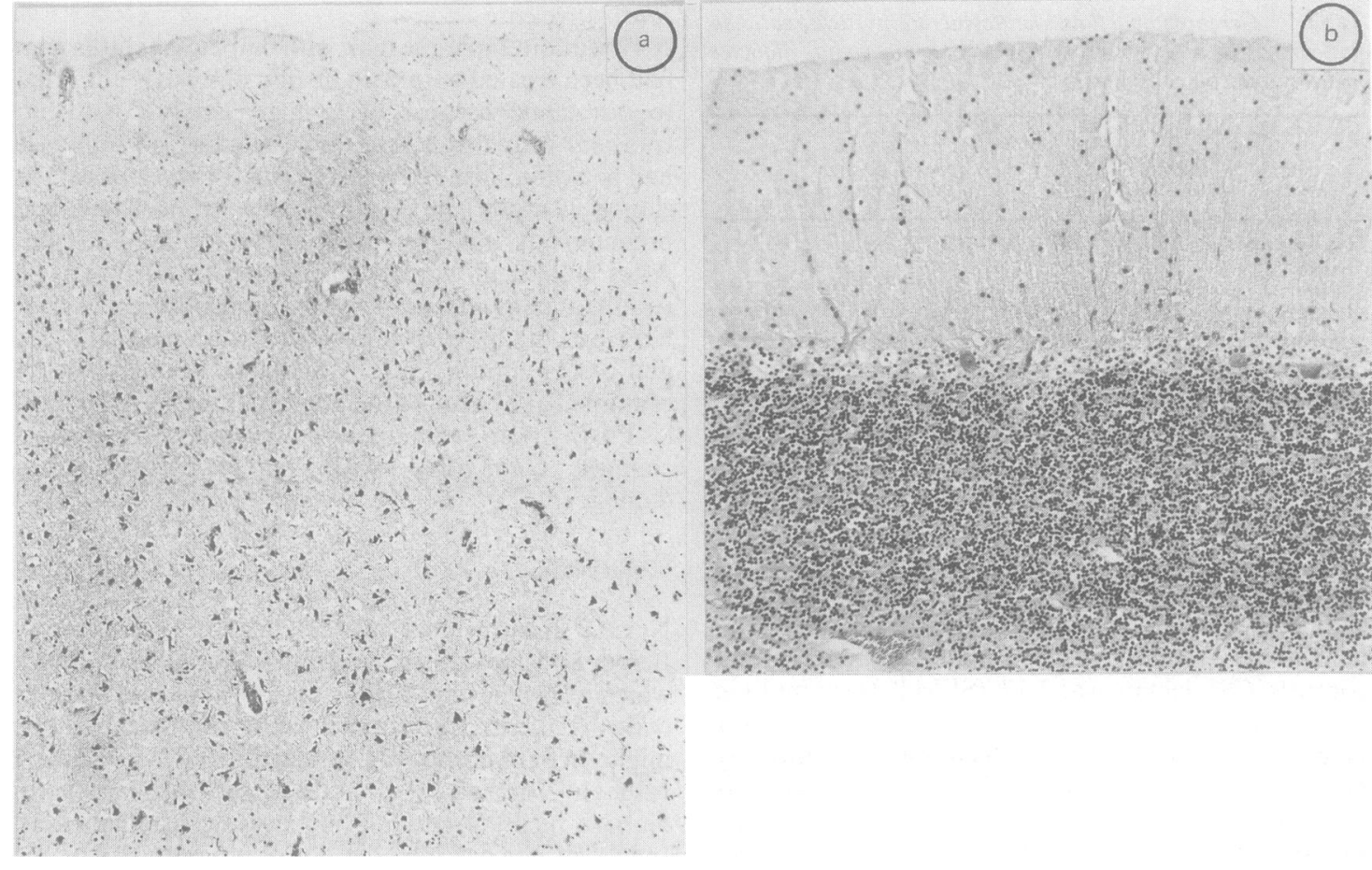

Fig 2 (a) Parietal cortex showing dark neurons and interstitial oedema of all cell layers $(H \& E \times 65)$. (b) Cerebellum showing marked loss of Purkinje cells ( $H \& E \times 90)$.

lopathy. ${ }^{7}$ In the present study, CSF lactate increased in diabetes mellitus even without any disturbance of consciousness, but it did not exceed $2.05 \mathrm{~m} \mathrm{~mol} / 1$. Thus, CSF lactate greater than $2 \cdot 1 \mathrm{~m} \mathrm{~mol} / 1$ seems to indicate derangement of glucose metabolism in the brain. CSF lactate pyruvate ratio in treated-hypoglycaemia was not significantly higher than controls. From our present data and those of Berger and Fawer ${ }^{1}$ which showed CSF lactate pyruvate ratio and "excess" lactate are no more significant than lactate alone, it would appear that CSF lactate elevation $>2.1 \mathrm{~m} \mathrm{~mol} / 1$ provides a better index of hypoglycaemic or hypoxic brain damage.

As shown in a human study ${ }^{12}$ as well as in our experimental studies, ${ }^{13}$ hyperglycaemia per se does not disturb brain energy metabolism. Brain tissue lactate in non-ischaemic hyperglycaemic rats was $2 \cdot 61$, SEM $0.17 \mathrm{~m} \mathrm{~mol} / \mathrm{kg}$ which was slightly higher than 2.32 , SEM 0.15 in normoglycaemic rats. ${ }^{13}$ Similarly, CSF lactate in our diabetes mellitus patients was slightly higher than in controls. In contrast, CSF lactate elevated markedly $(>2 \mathrm{~m} \mathrm{~mol} / \mathrm{l})$ in those who recovered from hypoglycaemic coma. The experimental studies have clearly shown moderate elevation of brain lactate concomitant with reduced adenosine triphosphate even after recovery from profound hypoglycaemia. ${ }^{1415}$ Recently, Behar et $a l^{16}$ also reported that brain lactate increased progressively during recovery from hypoglycaemia and suggested two possibilities for the prolonged abnormality in brain lactate metabolism: (1) an accelerated glycolytic rate, and (2) an impaired mitochondrial function. Our present results showing greatly increased CSF lactate after the treatment for hypoglycaemic coma indicate that metabolic disturbance by hypoglycaemia persists for a longer time even after recovery from coma and that increased CSF lactate relates to the severity of mitochondrial dysfunction or damage.

In conclusion, CSF lactate slightly increased in diabetic patients without disturbance of consciousness, and more markedly in hypoglycaemic patients who recovered from coma, suggesting prolonged dysfunction of brain glucose metabolism by exposure to severe hypoglycaemia.

We thank Miss Y Sonoda for her technical assistance.

\section{References}

1 Berger JP, Fawer R. Cerebrospinal fluid (CSF) lactate and pyruvate in acute neurological situations. In: 
Bossart H, Lausanne $\mathrm{P}$, eds. Lactate in Acute conditions. Basel: Karger 1979:115-33.

2 Fujishima M, Sugi T, Choki J, Yamaguchi T, Omae T. Cerebrospinal fluid and arterial lactate, pyruvate and acid-base balance in patients with intracranial hemorrhage. Stroke 1975;6:707-14.

3 Sugi T, Fujishima M, Yamaguchi T, Choki J, Omae T. Lactate and pyruvate concentrations, and acid-base balance of cerebrospinal fluid and arterial blood in patients with cerebrovascular disease. Clin Neurol (Tokyo) 1975;15:5-14.

4 Oshima M, Sadoshima S, Yanai T, Yagi H, Fujishima M. Effect of oxygenation at high pressure treatment on clinical course and CSF lactate level in acute cerebral infarction. Jpn J Stroke 1988;10:208-14.

5 Busse O, Hoffmann O. CSF lactate and CT findings in middle cerebral artery infarction. A comparative study. Stroke 1983;14:960-3.

6 Fujishima M, Nakatomi Y, Tamaki K, Ishitsuka T, Kawasaki T, Omae T. Cerebrospinal fluid lactate and pyruvate concentrations in patients with malignant hypertension. J Neurol 1984;231:71-4.

7 Yao H, Sadoshima S, Fujii K, et al. Cerebrospinal fluid lactate in patients with hepatic encephalopathy. Eur Neurol 1987;27:182-7.

8 Ohman JL, Marliss EB, Aoki TT, Munichoodappa CS, Khanna VV, Kozak GP. The cerebrospinal fluid in diabetic ketoacidosis. $N$ Engl J Med 1971;284:283-90.

9 Ronquist G, Terent A. Cerebrospinal fluid markers of disturbed brain cell metabolism. Prog Neurobiol 1982;18:167-80.

10 Brierley JB. Brain damage due to hypoglycaemia. In: Marks V, Rose FC, eds. Hypoglycaemia. Oxford: Blackwell, 1981:488-94.

11 Siesjö BK. Brain Energy Metabolism. New York: Wiley, 1978:101-30.

12 Kety S, Polis BD, Nadler CS, Schmidt CF. The blood flow and oxygen consumption of the human brain in diabetic acidosis and coma. J Clin Invest 1948;27: 500-10.

13 Ibayashi S, Fujishima M, Sadoshima S, et al. Cerebral blood flow and tissue metabolism in experimental cerebral ischemia of spontaneously hypertensive rats with hyper-, normo-, and hypoglycaemia. Stroke 1986;17:261-6.

14 Agardh C-D, Folbergrova J, Siesjö BK. Cerebral metabolic changes in profound, insulin-induced hypoglycaemia, and in the recovery period following glucose administration. J Neurochem 1978;31:1135-42.

15 Abdul-Rahman A, Agardh C-D, Siesjö BK. Local cerebral blood flow in the rat during severe hypoglycaemia, and in the recovery period following glucose injection. Acta Physiol Scand 1980;109:307-14.

16 Behar KL, den Hollander JA, Petroff OAC, Hetherington HP, Prichard JW, Schulman RG. Effect of hypoglycaemic encephalopathy upon amino acids, high-energy phosphates, and $\mathrm{pH}_{\mathrm{i}}$ in the rat brain in vivo. $J$ Neurochem 1985;44:1045-55. 